\title{
THE RISE OF THE PHOENIX: Methodological Innovation as a Discourse of Renewal
}

\author{
David Wastell \\ Nottingham University Business School \\ Nottingham, UK \\ Tom McMaster \\ Information Systems Institute, University of Salford \\ Greater Manchester, UK \\ Peter Kawalek \\ Manchester Business School \\ Manchester, UK
}

\begin{abstract}
The imperatives on contemporary organizations to adapt to an uncertain and turbulent environment are intense. Resilience refers to the ability to cope with change through a continuous process of renewal. The pace of change is at least as great in the public as the private sector, with technology being integral to the UK government's modernization agenda. This represents a stiff challenge for the traditional, technically oriented IT department. Here we recount the history of one such department in a local government institution as it sought to reinvent itself to respond to these new demands. The development of an IS methodology, embodying a business and customer-centered approach, was seen as key to generating the required capacity to support strategic change in the wider organization. Although methodological innovation can be problematic, here it was brought off successfully. This was attributed to several factors, including the adoption of a participative action research approach and the commitment of senior IT management. Above all, the sense of crisis prevailing at the outset of the initiative was decisive. Crises present a major challenge to organizational sense-making; here the impending threat was interpreted positively as a proactive opportunity to develop a new strategic identity. A resilient "discourse of renewal" was kindled, with the need to build new technical capabilities through methodological innovation playing a central part.
\end{abstract}

\footnotetext{
Please use the following format when citing this chapter:

Wastell, David, McMaster, Tom, Kawalek, Peter, 2006, in International Federation for Information Processing (IFIP), Volume 206, The Transfer and Diffusion of Information Technology for Organizational Resilience, eds. B. Donnellan, Larsen T., Levine L., DeGross J. (Boston: Springer), pp. $239-256$.
} 
Keywords Organizational resilience, public sector, modernization, methodological innovation, action research, discourse of renewal, organizational crisis, micropolitics

\section{INTRODUCTION}

Every 500 years (or $540,1,000,1,461$, even 12,994, depending on the cultural context!), the legendary and beautifully plumaged Phoenix' self-cremates in its nest of cinnamon twigs, rising again to embalm the ashes of the old Phoenix in an egg of myrrh. Something of a Jungian archetype symbolizing the universal cycle of birth, death, and rebirth, the Phoenix figures widely as a cultural motif in religious ritual and imagery, classical and popular culture, flags and other symbolic artefacts. Renewal is the theme of this paper, in the more prosaic context of organizational resilience, which refers to the internal processes of equilibration that ensure the continuity of systems in the face of destabilizing events, shocks, and disturbances (i.e., stressful environmental challenges that threaten viability). Faced with such threats, a variety of reactions are possible, but of interest here is the potential for renewal, reinvention, or reconstruction to better meet the exigencies of a changing world. Through a "discourse of renewal," organizational entities, like the Phoenix, may rise again from their metaphorical ashes. Here we tell the story of how one such group, the IT department in a large public sector bureaucracy, undertook its quest for self-renewal. The case is of particular relevance in the context of IFIP WG8.6, as the development of an innovative IS methodology was the key to survival and prosperity. While the fortunes of the IT group provide the main narrative interest, its transformation has afforded new capacities which have augmented the resilience of the organization as a whole. Indeed, this was the key to the department's regeneration strategy.

In general, these are certainly interesting times for the IS/IT function. As organizations come to rely more and more on technology to deliver strategy and drive performance, the pressures on IT departments have steadily intensified (Fitzgerald et al. 2002). The threat of outsourcing looms large, serving to encourage those who might falter or fail. A challenging world indeed for the traditional IT department, immured in the basement of the organization. The imperatives for organizational change are at least as pressing in today's public sector as in the commercial sphere. The injunctions to reform and modernize public services are strident and ubiquitous, encapsulated in the global mantras of the new public management (Wastell 2006). Technology is integral to this change agenda. The vocabulary of eGovernment depicts information and communication technology (ICT), in language bordering on the evangelical, as the

${ }^{1}$ Firebird, Benu, Fenghuang, Ho-oo, or Yel according to ancient Russian, Egyptian, Chinese, Japanese, and Native Americans, respectively. As a symbol of renewal, examples are easily found, including the flags of Atlanta and San Francisco, both depicting the Phoenix surmounting a wreath of flames, symbolizing renaissance from human and natural disaster. This paper itself is a Phoenix, a palimpsest resurrected from the ruins of so many earlier versions! 
talismanic enabler of transformation (Kawalek and Wastell 2005). ${ }^{2}$ Here, the IT/IS function in a metropolitan local authority recognized that it was becoming increasingly marginal to the operations of the organization as a whole. It did not provide the capability required to support an ambitious program of strategic change that had been articulated in the authority's business strategy, or to respond to the ever-pressing injunctions of the external modernization agenda. Faced with this crisis, rather than adopting a defensive stance, they embarked upon a proactive process of internal reforms in order to reposition themselves in the strategic vanguard of the organization. At the heart of this was a new methodological approach to the development of information systems embodying a more business and customer-oriented ethos.

Innovation in IS practice is a problematic endeavor. Research on the implementation of new software tools evidences substantial resistance and frequent rejection (Iivari 1996; Orlikowski 1993), and much greater resistance is to be expected for complete methodologies given the scale of change involved (Hardgrave et al. 2003). Methodologies are more embracing than individual tools, requiring substantial restructuring rather than more localized changes. Huisman and Iivari (2006) report that methodologies tend to be more favored by managers than developers. Nandhakumar and Avison (1999) describe methodologies as a "necessary fiction" of symbolic status but too mechanistic to be of practical use. The critical studies of Kautz and McMaster (1994) and Wastell (1996) also narrate the vicissitudes of implementing structured methods. Fitzgerald et al. (2002) comment generally on the widely reported low level of method use, especially among experienced developers, echoing the general scepticism found in earlier studies (e.g., Fitzgerald 1998). These authors provide a useful framework for understanding the technical and political rationalities of "methods-in-action" and of the barriers that militate against the adoption of formalized approaches (e.g., the messiness and contingencies of real-world practice). Significantly, they highlight the political role played by formalized methods in professionalizing and legitimizing IS practice, paving the way for a more proactive role of IS in strategy formulation. The comfort/confidence factor is also emphasized, recalling the tendency of developers to "fetishize" methods, as recounted in Wastell (1996).

The dominant theoretical approach for the study of innovation in our field draws on the classical diffusionist framework of Rogers (1995), which has spawned the influential technology adoption model (Davis et al. 1989). Recent papers applying TAM to methodological change include Templeton and Byrd (2003) and Hardgrave et al. (2003). In essence, Rogers portrays innovation as a decision-making process in which individual adopters decide whether to embrace a new technology or not. The limitations of Rogers for understanding organizational innovation have been addressed by Van de Ven (1995), who highlights the step-change in complexity of organizational processes as opposed to individual adoption decisions. A more recent critique in an organizational context is provided by Lundblad (2003). The limitations of technology focused accounts and the need to examine the broader social context of IS innovations has also been emphasized by Kautz and Nielsen (2004). In this paper, we develop this discourse further by

${ }^{2}$ The recently published National IT Strategy, for instance, is emblematically entitled "Transformational Government Enabled by Technology" (Cabinet Office 2005). eGovernment (in the UK) is seemingly passé; tGovernment's the thing! 
reframing methodological innovation as predominantly an issue of organizational change, rather than technology adoption. This reframing brings to bear fresh theory from organizational science to cast new light on the problematics of innovation, in particular on the key role of organizational crises as the drivers of change.

The role of crises as instigators of change is hardly novel. Gersick's (1991) concept of punctuated equilibrium reflects the idea that the status quo will prevail in organizations unless there is a perceived need for change. Shocks are required to overcome this organizational inertia; "only when people reach a threshold of sufficient dissatisfaction with existing conditions, [will] they initiate action to resolve their dissatisfaction" (Van de Ven 1995, p. 275). The concept of organizational crisis is a nuanced one, going beyond the stereotypical notion of a seismic event, arising out of the blue. Such crises may arise from many sources (Kovoor-Misra et al. 2001): from technological disasters, from declining performance, but equally from growth too (developmental crises). While they may often be abrupt, unexpected and infrequent, equally they may be slow-moving, predictable, and recurrent. Common to all usages is the presence of a serious existential threat to the organization, arising from some exogenous or endogenous source, together with a degree of time pressure to respond (Kovoor-Misra et al. 2001). Crises may evoke a range of organizational responses from passivity to active coping. Defensive reactions all too often occur (Wastell 1999) when severe threats are confronted, including a state of paralysis described as "threat-rigidity" (Barnett and Pratt 2000). But crises may provide innovatory opportunities too: to deal with problems, to unfreeze old behaviors, to develop new ways of understanding and acting (Kovoor-Misra et al. 2001). Seeger et al. (2005) refer to this positive, post-crisis orientation as a discourse of renewal, its hallmark being a practical, prospective orientation to the future rather than an exculpatory and defensive attitude to the past.

Here we advance the general argument that methodological innovation should be understood as organizational change. The outcome of the initiative will be contingent on a range of nontechnical, organizational factors, which are more fundamental than the technological features of the innovation itself. In particular, there must be a potent sense of purpose, a crisis, driving the change, with the methodological innovation seen as a developmental opportunity, a progressive solution to the impending threat (KovoorMisra et al. 2001). Without this clarity of purpose and the keenly felt need to change, the attempt to innovate is likely to founder. The paper will cover the following broad areas. It will first describe the local context and the change process within the field setting before moving on to outline the results of this process. We will conclude by reflecting on what has been learned regarding the practical accomplishment of resilience and the nature of methodological innovation as a process of organizational change.

\section{ANTECEDENT CONTEXT AND METHODOLOGY}

The setting for the project is Salford City Council (SCC), a local government institution in the North West of England. Salford is a medium-sized city of around 250,000 inhabitants, and one of 10 local authorities making up the Greater Manchester conurbation. Like most local authorities in Britain, $\mathrm{SCC}$ is organized around key service areas, such as housing, social services, education, etc. There is a central IT services department (ITSD) staffed (at the outset of the story) by around 20 professionals organized in a number of specialist teams (e.g., software development, PC support). 
The story begins in the summer of 1999, shortly after the "failure" of ITSD to implement a CASE tool in a project (CAPELLA) supported by European funding. This antecedent failure is significant and will be returned to in the "Discussion." More details of CAPELLA may be found in Kautz et al. (1999), with a recent analysis of its miscarriage appearing in McMaster and Wastell (2004). In short, CAPELLA foundered because key stakeholders (practitioners especially) were uncommitted to the use of the CASE tool, which became increasingly seen as marginal to the urgent, practical problems facing ITSD (e.g., Y2K, legacy system maintenance). Of particular salience here was the clarion call in CAPELLA's final report for "strong alignment of the introduction of new technologies [with] short term demands [and] long term business goals" (Williams and Willetts 1999, p. 3). The report went on to recommend the adoption of a new systems development methodology. The need for a more businessoriented approach had also been articulated in the City's Information Society Strategy, published earlier that year. The Strategy's aim was to harness the potential of IT to improve the social and economic well-being of the people of Salford. It was recognized that a business process reengineering (BPR) approach was required to implement the strategy, focusing on the innovative use of IT to realize radical business change. Quoting again from the CAPELLA report:

Externally, requirements from Central Government to improve services and provide greater value for money, involving constant re-engineering of business processes, has placed Information Technology in a position of increasing expectations to aid such transformations...not only in delvering improved products, but in strengthening its capacity in coping with changes arising for new demands and expectations. (Williams and Willetts 1999, pp. 5-6)

The miscarriage of CAPELLA and the publication of the Information Society Strategy form key antecedent features of the local context. It is also important to consider change events in the wider environment of the sector as a whole (Meyer et al. 1995). Here the most potent forces relate to the emergence of eGovernment in the UK, which may be traced back to the publication of the central government's 1999 white paper, "Modernising Government" (Cabinet Office 1999). This challenged all public sector organizations (including local government) to deliver efficient and responsive citizen-centered services, and IT was seen as critical to achieving these aims. The ambitiousness of the agenda was reflected in the target to electronically enable 100 percent of relevant services, initially by 2008 but subsequently accelerated to 2005 . Various national initiatives lent force to the modernization program. A so-called "Pathfinder" initiative was launched in 2001, whereby significant new funding was set aside for local authorities able to demonstrate a leading position in relation to some aspect of eGovernment.

Rather than adopting an external methodology, ITSD took the decision to develop its own (to be known as SPRINT) and the approach taken was action research (AR). Greenwood and Levin (1998) define AR as research carried out by a team of professional researchers in collaboration with members of an organization or community, the aim being to support action leading to a more just or satisfying situation for the stakeholders. Given its highly applied nature, the discipline of IS has long been seen as a natural application domain for action research (Baskerville and Wood-Harper 
1998), the typical usage being to develop new systems (e.g., Davison 2001; Simon 2000). It is unusual to use AR as a tool for constructing new methodological approaches. Of note is a study by Mathiassen (2002) in which an AR-like approach was used to support and improve IS development practices in four organizations. Mathiassen refers to his mode of enquiry as collaborative practice research.

Work commenced in July 1999, spearheaded by a small AR team led by the head of ITSD, and also comprising two local academics (who had worked with SCC before, during CAPELLA) and several developers, including one section leader. The remit of the academics was to bring to bear their prior knowledge of IS methodology, to support the use of the emerging framework in practice, and to facilitate its further development. The academics also took prime responsibility for recording ideas and experiences, and acted as custodians of the evolving documentation of the methodology as it took shape. The role of the practitioners was to codevelop the emerging framework, contributing to its progressive refinement, applying it in practice, and reflecting on its strengths and weaknesses. The practical means of developing the framework was that of collaborative working and reflection, with all members of the team working closely together on a series of projects, using this shared experience as the basis for developing and refining the methodology. Much of this reflection was embedded in the work itself, during project meetings, informal discussions, etc., supplemented by ad hoc brainstorming sessions to capture key ideas and experiences. More formal workshops were also held off-site to discuss major developments to the methodology.

The following section will describe the history of the project. Table 1 provides a project time-line to support the narrative. It summarizes the main events that took place, in terms of internal developments and in the external environment (locally and nationally) that materially impinged on the work. The account has been constructed from the collective reflections of the AR team, corroborated where possible by contemporaneous documentation (e.g., workshop minutes, internal reports, policy documents). Formal interviews with key practitioners were carried out in the summer of 2004 to provide further reflection and corroboration, and to fill in any lacunae. Unless indicated otherwise, quotations in the text below were extracted from these interviews.

\section{THE SPRINT CHRONICLES}

As noted, the project was formally launched in July 1999, as one of the key work programs of the City's Information Society Strategy. BPR was seen as vital to delivering the Strategy's visionary aims: "to improve cost effectiveness, service responsiveness and co-operation across the City, joining-up service delivery across agencies" (City of Salford 1999, p 1). Interviewed in 2004, the head of ITSD reflected on the original motivation for the project:

We were largely a traditional, technically orientated IT department; our people were predominantly technology people. We did try to understand the Council's strategic agenda but our alignment was vague. We were seen as people who built software, put PCs on desks and installed networks rather than adding strategic value. 
Another senior officer in ITSD, subsequently to head up the BPR team, described the situation in very bleak terms:

We went through a strange phase in the olden days. Departments increasingly thought they could do things for themselves, they could buy their own system and didn't need ITSD. This was leading us to stagnation in the way we were moving; we had no role or identity. Y2K also diverted us. We were hardly involved in the SAP procurement; we were too busy on $\mathrm{Y} 2 \mathrm{~K}$. We were feeling very marginal at the time.

In the eyes of the head, the aim of the project was bold and radical, nothing less than to reposition IT as a "true enabler of business transformation." Work began based on prior BPR work by the academics, largely in the commercial sector (Wastell et al. 1994). This was reviewed by the AR team and a draft methodology produced in early October 1999, which was christened SPRINT (Salford Process Reengineering Involving New Technology). In mid-October, a paper was presented by the head of ITSD to SCC's senior management team recommending adoption of SPRINT and its deployment on a comprehensive program of BPR projects. Significantly, no additional resource was requested in order to carry out this ambitious initiative; it would be done within the existing IT budget. The recommendation was accepted and an internal BPR team was constituted to carry forward the work, in conjunction with the academics. In effect, this formalized the AR team. The first project carried out was crucial in proving and refining the methodology. It focused on the administrative team supporting the committee-based decision-making structures operational within the Council at that time. Work began in late October, and concluded in January 2000 with the production of a set of radical proposals. Far from mere office automation of the clerical function (as had been originally envisaged), the proposals focused on the need to support the role of elected representatives in decision-making through the creation of a new information management function. More details of this inaugural project, including its evaluation, may be found in Kawalek and Wastell (2005).

Two further projects were quickly instigated early in 2000 , in the Housing and Treasury departments respectively. The second of these was a notable success. A key problem facing Treasury was the high number of unanswered telephone queries, identified in a report the previous autumn. The department had also performed very poorly in an external audit of its housing benefits process, having been awarded the bottom grade by the Housing Benefits fraud inspectorate. Users participated fully and vigorously in the BPR process, including carrying out a comprehensive process mapping exercise, largely unaided by the BPR experts. Workshops were held on a regular basis, and the work was enthusiastically led by a senior user. The main reengineering recommendation was to create a dedicated customer contact center for Treasury, which went live in October 2000. The transformation in Treasury's housing benefit service effected by the center was ultimately reflected in the award of a four-star rating (Table 1). Two further BPR projects were launched over the summer of 2000 and adaptations made to SPRINT to add new tools, including tailoring its use for customer-centered analysis and contact center design. 


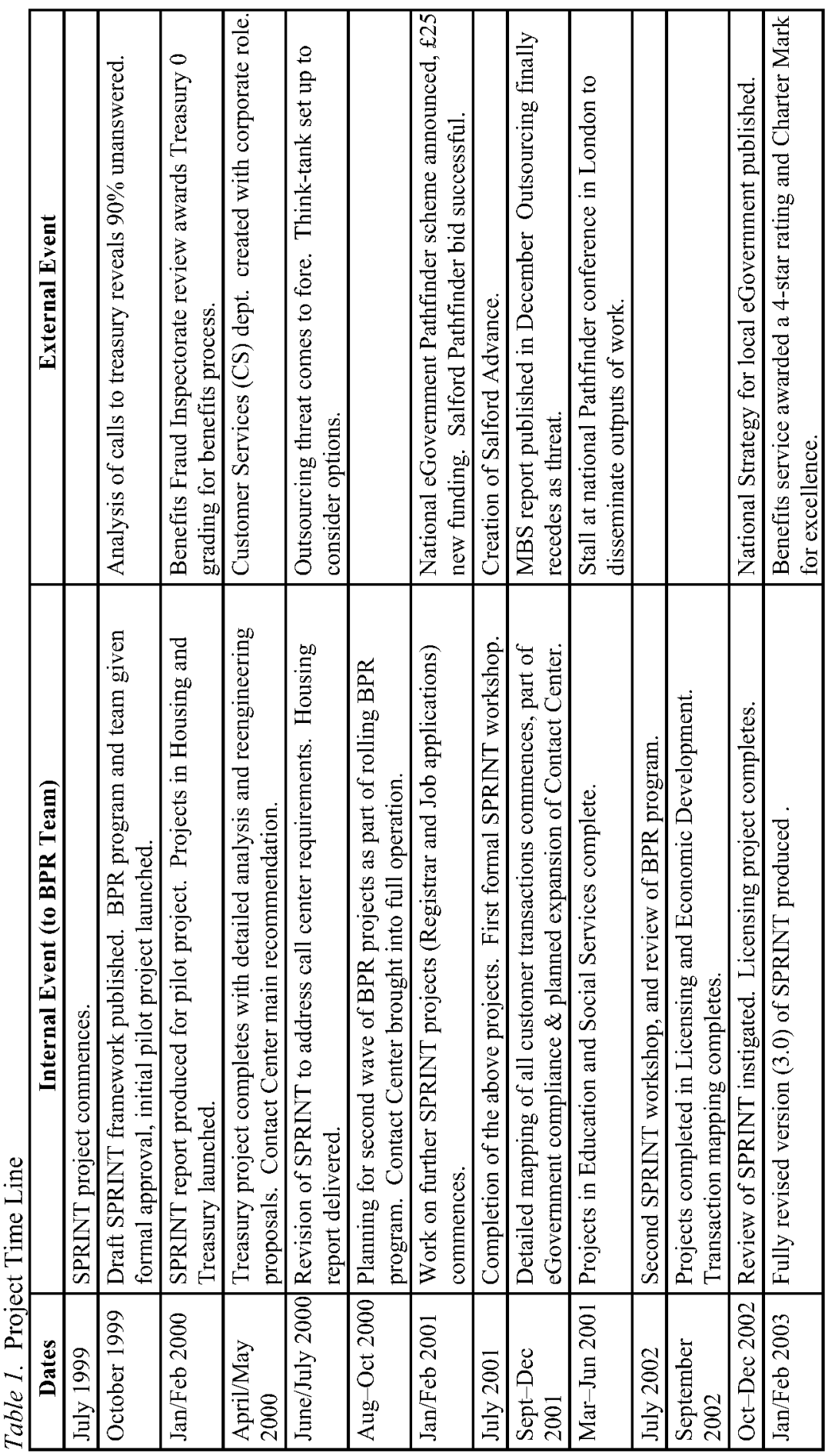


Three external developments were influential over the ensuing 12 months. First was the appearance of a serious threat to outsource the IT function. To forestall this, ITSD proposed setting up a think-tank to examine the implications fully, and an independent assessment was also commissioned from Manchester Business School (MBS). SPRINT itself was important in deflecting the threat. The head of ITSD commented: "SPRINT allowed me to say to senior management that we're repositioning ourselves, we're addressing our weaknesses, that he should trust the in-house service" (Slatcher 2002). Although the outsourcing threat persisted for over a year, ITSD's dogged resistance prevailed and by the time the MBS report was published the threat had receded. The second important development was the announcement of the national Pathfinder initiative (see above) in early 2001. SCC was one of the successful contenders, with SPRINT featuring centrally in their bid. Substantial funding $(£ 0.5 \mathrm{~m})$ was obtained to accelerate SCC's BPR program to "commodify" the SPRINT methodology into a resource for the local government community as a whole, and to mentor other local authorities in IT-enabled business change. The final development was the success of the embryonic contact Center which came to be seen as a model for $\mathrm{SCC}$ as a whole to improve its customer relations. It was established as a corporate facility, with plans to extend the range of services to be transferred into the center.

A formal workshop was held in July 2001 to review these early experiences with SPRINT, to update and refine the methodology accordingly, and to plan the Pathfinder activities in detail. It was attended by all of the AR team, as well as several other IT staff. The meeting was positive and constructive. Many aspects of SPRINT were felt to be particularly valuable ( e.g., the emphasis on process mapping and the value of direct observation- "light ethnography"-in actual work settings). Several action points resulted, including the need to develop some new components. The mood had lifted. The head of the BPR team reflected:

Things came together nicely. SPRINT arrived at the right time, and there were also areas in the authority that needed major change. We saw the situation as an opportunity to flex our muscles. SPRINT helped to crystallize our new role. We were lucky that we decided to do BPR, and then the crises came in Council Tax and Housing Benefits, and then eGovernment. There was a lot of change going on at the time... we were needed.

A radical reorganization of IT services was instituted in the summer of 2001 . The more routine activities of legacy system maintenance and PC support were split off into separate sections, and a new organizational entity was created, emblematically christened "Salford Advance" to emphasize its progressive role. Salford Advance subsumed the BPR team, a small research and development group, and training. It was a clear step toward realizing the head's vision of a more strategic role for IT, and also helped in creating focus and dedicated resource for the Pathfinder work.

Over the following year, SPRINT was internally deployed on a further 12 projects and most of the enhancements identified at the first workshop were implemented. Externally, over 40 other local authorities were mentored as part of the Pathfinder work. A second SPRINT workshop was held in July 2002, to review progress and identify areas for development. The full AR team was again present, supplemented by other 
ITSD staff who had been involved in BPR project work. Several major new SPRINT features were proposed, by both practitioners and academics. The relationships between SPRINT, eGovernment, and other change initiatives, such as "best value" (Boyne et al. 2002), were also much discussed. An independent evaluation was subsequently instigated of all on-going and completed projects. Fourteen projects had been completed or were in progress. All projects had produced SPRINT outputs, and four had reached implementation in full or in part. Three of these had resolved into call center implementations, reflecting alignment with the emergent corporate plan alluded to above. Four projects were still in progress; six had reached the end of phase 1, with useful analysis having been produced, but no decision to move into implementation. In part, the evaluation report attributed these areas of blockage to the presence of a complex and fluid agenda of change within SCC, with a range of initiatives (best value, eGovernment) competing for resources and attention.

Regarding SPRINT itself, the report commented favorably as follows:

The BPR team followed the methodology closely and deeply. The mapping of business processes was seen as a useful way of engaging the users and checking whether the BPR team had understood the process as it existed. The methodology does offer a series of tasks and tools that are valued by those who use them. By being "road-tested" within an actual organisation, the methodology has gone beyond its academic origins. If it has been found wanting it is mainly in its larger ambitions. The "real world" of organisations puts very strict limits on how a methodology can create change-it is competing with too many other things that are not easily factored into methodological design.

The report made several recommendations for the further development of SPRINT including reorganizing the material in a user-friendly way, simplifying the language, and explicitly relating SPRINT to parallel initiatives. As a result, SPRINT was thoroughly revised, with the new version (SPRINT3) completed in January 2003. It was rewritten to be more accessible, and it was given an explicit eGovernment cast. A number of new features were introduced and phase 3 replaced by a "hand-over step" at the end of phase 2. At this point in time, the action research project had largely completed its work. The prime purpose had been to generate an effective BPR methodology and SPRINT, representing the collaborative efforts of practitioners and academics alike, was the product of this work. Appendix 1 provides a brief overview of SPRINT, including its underlying philosophy; further details and a full description are publicly available on various web-sites (see below).

The detailed history thus closes here and we will end with a brief summary of how matters have moved on since. A steady stream of new BPR projects has flowed, and by the summer of 2004, a cumulative total of 22 projects had been carried out. A further review of the methodology was carried out in mid-2004, strengthening its customerorientation and enhancing the visual appeal of the documentation; this new version was published later that year on a dedicated "gov.uk" web-site. ${ }^{3}$ External interest in

${ }^{3}$ See www.sprint.gov.uk. Earlier versions may be inspected on www.wastell.org/SPRINT1 and www.wastell.org/SPRINT3. 
SPRINT, inspired by the Pathfinder work, has continued to grow, and a user group has been formed, which held its inaugural meeting in April 2004. The group is chaired by a senior practitioner. At the time of writing, there are around 200 individual members, representing over 70 different organizations. The interview with the head of ITSD in 2004 eloquently expressed how the fortunes of ITSD had turned around since the dark days of 1999. The Head commented on the role of SPRINT within this transformation as follows:

SPRINT helped profoundly to reposition IT as a true enabler of business transformation. We're now on the top table. The chief wxec now recognizes that BPR is key to achieving strategic aims and objectives. It has put us on the strategic change management map. As an example, we were central in developing a new business model for council services, called "Think Customer." It's all about joined up service delivery. We're even on the treasurer's radar now. The Council is constantly seeking substantial budget savings and we're seen as the "ghost-busters," the ones that can fill the hole. We now make a real difference to delivering the Council's agenda.

\section{DISCUSSION}

Let us begin by reinvoking our archetype, in the guise of Robert Aldrich's 1965 movie The Flight of the Phoenix. At the height of the drama, the following dialogue takes place in the blistering desert sun, as the cast come to terms with the receding possibility of rescue. They contemplate an improbable plan to save themselves, by cannibalizing a new plane from the wreckage of the old, to bring off an audacious escape:

Towns: Your theory's fine. But you get this: that engine's rated 2000 horsepower, and if I was ever fool enough to let it get started, it'd shake your pile of junk into a 1000 pieces and cut us up into mincemeat with the propeller....

Towns: I've lost five men Lew....are you asking me to kill the rest of them trying to get that death-trap off the ground. I can't do it Lew, it won't work, it just can't work!

Lew: All right, it can't. Maybe it can't and we'll all be killed. But if there's just one chance in thousand that he's got something, boy I'd rather take it than just sit around here, waiting to die.

Just as these maroons took fate into their own hands, so too did a "discourse of renewal" take hold in ITSD, equally beleaguered at the outset of our narrative; they also chose not to "sit around here, waiting to die." SPRINT was the department's Phoenix, fashioned from the ashes of CAPELLA, and compared to the limited innovation achieved in that ill-starred project (McMaster and Wastell 2004), the methodology provided the vehicle for a fundamental reinvention of ITSD's role and identity. SPRINT has been enthusiastically adopted and a dedicated BPR team now spearheads its 
deployment on a large portfolio of projects, and has done so for more than 5 years. The seat at the organization's "top table" has at last been secured.

The aim of this paper was to introduce briefly the SPRINT methodology, emphasizing the process of its production, and to use the case to reflect on the much-bruited troubles of methodological innovation from an organizational change perspective. How, then, may we account for the transformation in ITSD, its accomplishment of successful innovation against the usual grain? Two familiar success factors immediately stand out. We know only too well from the sad litany of failed IS projects (Laudon and Laudon 2005) that two ingredients are vital to the success of any change initiative: the commitment of senior managers and the willing participation of staff. Both of these key conditions were clearly met here. The project was led passionately by the head of ITSD, who operated throughout as a "transformational leader," fully committed to bringing off the required changes (Bass 1985). The adoption of an action research approach is also significant. It has been argued that public sector organizations are more conservative than their private sector counterparts (MacIntosh 2003). Given its intrinsically participative nature, AR would seem particularly appropriate as a change methodology in such a context where there is a long-established culture of consensus and collegiality. Mustonen-Ollila and Lyytinen (2003) have found that the majority of IS process innovations originate from within the organization. Here, a core group of practitioners were engaged throughout SPRINT's development; the methodology was not imposed from without, but developed endogenously by the practitioners and the academics working in close collaboration. The AR methodology, with all key actants involved in the cyclical learning process that drove its development, meant all internal stakeholders were naturally drawn into the innovation process and held in place, with SPRINT at the center of this strengthening network. Over time and a sustained series of deployments, this led to its ultimate congealment as a "black box" (Latour 1987), a fully accepted, organic part of the life of the department.

But this analysis is only part of the story. Other key factors were clearly at work. We argued in the "Introduction" that the turning point of any organizational innovation process is the presence of a threatening stimulus. Without such a sense of crisis, inertia will tend to prevail and any mobilization for change (at whatever level) will quickly peter out. Such organizational crises need not be abrupt, cataclysmic events; they may emerge slowly, with growing force, as the adaptive relationship between the organization and its environment steadily breaks down over a period of time (Kovoor-Misra et al. 2001). Moreover, crises may not necessarily represent direct, imminent threats. Barnett and Pratt (2000) introduce the concept of an autogenic crisis to refer to a latent threat, created or amplified by managers in order to concentrate minds, to develop solidarity and engender motivation for change.

In contrast to CAPELLA, there was a much stronger sense of the need for radical change at the outset of the SPRINT era. The Information Society Strategy and the broader eGovernment imperatives presented a powerful challenge to ITSD to develop its role, to take a more central place in the City's strategic agenda. This was later combined with a sustained outsourcing threat, against which the development of new capacities (not easily replicated by an external agency) was a convenient tactical counter. In many ways, the crisis facing ITSD at the end of the 1990s was an autogenic one; there were clear symptoms but at that point the crisis was implicit, the threat of outsourcing was yet to come, and the eGovernment agenda still embryonic. Nonetheless, times were clearly a-changing, with the traditional technology-focused paradigm seemingly ill-fitted 
for the brave new world of modernized public services. A challenging new role for IT at the center of the business was slowly taking shape, in prospect at least. New organizational competencies were needed to respond effectively to the pressures to reform services, and ITSD saw itself as central to this agenda. The impending crisis, still theoretical at that time, could have been resisted. There was no necessity to embrace the need for change: a defensive process of denial could have set in, with ITSD ignoring the emerging imperatives. Alternatively, the challenges could be viewed positively, as a developmental opportunity (Kovoor-Misra et al. 2001; Seeger et al. 2005).

Here the latter response prevailed; a proactive opportunity for growth and an expanded role was perceived. The sense of latent crisis prevailing at the project's outset produced a decisive alignment of all key internal actors within ITSD, both management and staff, around the need for change, and held them in place over a sustained period of transition, during which the latent threats translated into real ones, and waxed in their power. Within the initial "problematization" (Latour 1987), a discourse of renewal took shape, operationalized in the development of a new methodology. Seeger et al. (2005) identify several characteristic features of such discourse: a positive orientation to the future rather than defensive rumination; a focus on constructing new technical faculties, methods, and procedures; and an improvisational pragmatism emphasizing expediency and flexibility, rather than rational, top-down planning. The role of the leader is critical. Organizational change is par excellence an act of sense making (Weick 1995): basic assumptions about role and identity must be reframed and reinterpreted. The leader's prerogative is to provide this new interpretive schema, not only to inspire through passion, but to create new meaning during times of uncertainty, to make sense of the world for those in doubt and confusion. The clear vision of the head of ITSD around the need for change and for the development of a BPR capability was decisive. He was the prime orator of the renewal rhetoric.

Improvisation and resourcefulness are also critical ingredients of renewal discourse, the determination to persevere and to succeed, expediently using whatever is to hand. How vividly Aldrich's film depicts human ingenuity in the chutzpah to extemporize an entirely new plane from the shattered remnants of the old, a plane that flew against all odds and due scepticism. Much innovation, as in ITSD, is un-mandated, arising spontaneously from the middle and lower levels of organizations (Borins 2002). Change at the meso-level requires special leadership characteristics, captured well in Weick's (1990) notion of bricolage, which offers a refreshing counterpoint to the conventional view of change as top-down, rational, and planned. For mid-level innovation, where resources are scarce and formal authority limited (Borins 2002), leadership is as much about improvisation and expediency as inspiration and vision: "the main function of any leader is to draw organization out of the raw materials of life by using ingeniously whatever is at hand" (Weick 1995, p. 352). The middle manager who would be innovator, rather than apparatchik, must have something of the subtlety and agility of the trickster about him (Hyde 1998). Examples abound here of opportunism and improvisation in the leadership provided by the head of ITSD, at least matching his visionary rhetoric. These include his shrewdness in exploiting crises (for both external and internal effect), the tactical alignment of SPRINT with the emergent customer contact center, the artful deflection of the outsourcing threat, and the audacity to conjure from thin air both a BPR capacity and a major change program. 


\section{CODA}

In this paper, we have linked two phenomena not at first sight correlated, organizational resilience and methodological innovation, through the common concept of organizational crisis. We have seen how renewal discourse is integral to resilience; how the survival of ITSD depended on the determination of its staff to reinvent themselves, to take up the challenge of a new and enlarged role, a role only they foresaw with any clarity. As a result, the organization as a whole has acquired a new capacity (for BPR) which in turn has enhanced its resilience, as the turnaround in Treasury neatly demonstrates. But the degree to which resiliency can be designed or enhanced by external intervention is a moot point. The limits are certainly clear from the present story. To a large extent, the development of Salford's BPR capability sprang from a unique configuration of chance, historical contingency, and human virtuosity. The emergence of SPRINT exemplifies innovation thriving on hardship, and the resilience of ITSD is the product of this same adversity. Had there been a conscious, top-down initiative to build capacity, the outcome might well have been very different, with additional bureaucracy and a surfeit of resources stifling, rather than stimulating, entrepreneurship, engendering sclerosis not resiliency. SPRINT itself is not a portable commodity: its efflorescence in Salford is inseparable from the unique historical processes of its development there; simply transplanting it would not, in itself, replicate the same capability (McMaster and Wastell 2005).

In general, we have noted that IS innovations often fail to take root, rapidly falling into desuetude if indeed they are ever used in earnest. Through our direct engagement in a project running against the normal trend, we have been able to construct the micropolitical causal narrative underpinning one instance of successful innovation. Lacking ethnographic grounding, such granularity of detail and understanding is necessarily absent in the high level conceptual models that typify much theory in our discipline. Generalizing with caution, we contend that a cogent sense of crisis is a necessary condition for any successful organizational change, of which methodological innovation represents but a specialized instance. The outcome of such efforts will critically depend on the degree of alignment between the innovation and the resolution of some impending threat, real or indeed latent. Where the methodology forms part of a discourse of renewal, the prospects are auspicious; otherwise, the prognosis is less hopeful. In contrast to CAPELLA, the success of SPRINT shows that radical IS innovation is feasible where there is a strong sense of solidarity and common purpose, with the innovation addressing an acknowledged crisis and the change propelled by the practitioners themselves, with resourceful and determined leadership.

\section{References}

Avison, D., Wood-Harper, A., Vidgen R. T., and Wood, J. R. G. "A Further Exploration in to Information Systems Development: The Evolution of Multiview 2," Information Technology \& People (11), 2998, pp. 124-139

Barnett, C. K., and Pratt, M. "From Threat-Rigidity to Flexibility: Toward a Learning Model of Autogenic Crisis on Organizations," Journal of Organizational Change (13), 2000, pp. 74-88. 
Baskerville, R., and Wood-Harper, A. T. "Diversity of Information Systems Action Research Methods," European Journal of Information Systems (7), 1998, pp. 90-107.

Bass, B. M. Leadership and Performance Beyond Expectations, New York: Free Press, 1985. Boyne, G., Day P., and Walker R. "The Evaluation of Public Service Inspection: A Theoretical Framework," Urban Studies (39), 2002, pp. 1197-1212.

Borins, S. "Leadership and Innovation in the Public Sector," Learning and Organizational Development Journal (23), 2002, pp. 467-476

Cabinet Office. "Modernising Government," Stationary Office, Great Britain, 1999.

Cabinet Office. "Transformation Government Enabled by Technology," Norwich, UK: HMSO, 2005.

City of Salford. "People Not Technology," Internal Policy Paper, Salford City Council, 1999.

Davenport, T. Process Innovation: Reengineering Work Through Information Technology, Cambridge, MA: Harvard Business School Press, 1992.

Davis, F. D., Bagozzi, R., and Warshaw, P. "User Acceptance of Technology: A Comparison of Two Theoretical Models," Management Science (35), 1989, pp. 35, 982-1003.

Davison, R. "GSS and Action Research in the Hong Kong Police," Information Technology \& People (14), 2001, pp. 60-77.

Fitzgerald, B. "An Empirical Investigation into the Adoption of Systems Development Methodologies," Information and Management (34), 1998, pp. 317-328.

Fitzgerald, B., Russo, N., and Stolterman, E. Information Systems Development: Methods in Action, New York: McGraw-Hill, 2002.

Gersick, C. "Revolutionary Change Theories: A Multi-Level Exploration of the Punctuated Equilibrium Paradigm," Academy of Management Review (16), 1991, pp. 10-36.

Greenwood, D. J., and Levin, M. Introduction to Action Research: Social Research for Social Change, London: Sage Publications, 1998.

Hammer, M. "Reengineering Work: Don't Automate, Obliterate," Harvard Business Review, July-August 1990, pp. 104-112.

Hardgrave, B. C., Davis, F., and Riemenschneider, C. K. "Investigating Determinants of Software Developers' Intentions to Follow Methodologies," Journal of Management Information Systems (20), 2003, pp. 123-151.

Huisman, M., and Iivari, J. "Deployment of Systems Development Methodologies: Perceptual Congruence between IS Managers and Systems Developers," Information and Management (43), 2006, pp. 29-49.

Hyde, L. Trickster Makes this World, New York: North Point Press, 1998.

Iivari, J. "Why Are CASE Tools Not Used?," Communications of the ACM (39), 1996, pp. 94-103.

Kautz, K., Kawalek, P., Willets, M., McMaster, T. Wastell, D., and Williams, C. "Using CASE to Enhance Service Performance in a Local Authority: The CAPELLA Project," in Proceedings of the of International Conference on Product Focused Software Process, Improvement (PROFES99), Oulu, Finland, 1999.

Kautz, K., and McMaster, T. "the Failure to Introduce System Development Methods: A FactorBased Analysis," in L. Levine (ed.), Diffusion, Transfer and Implementation of Information Technology, Amsterdam: Elsevier/North-Holland, 1994, pp. 275-287.

Kautz, K., and Nielsen, P. A. "Understanding the Implementation of Software Process Improvement Innovations in Software Organizations," Information Systems Journal (14), 2004, pp. $14,3-22$.

Kawalek, P., and Wastell, D. "Pursuing Radical Transformation in Information Age Government: Case Studies Using the SPRINT Methodology," Journal of Global Information Management (13), 2005, pp. 79-101.

Kovoor-Misra, S., Clair, J. A., and Bettenhausen, K. L. "Clarifying the Attributes of Organizational Crises," Technology Forecasting and Social Change (7), 2001, pp. 77-91. 
Latour, B. Science in Action, Boston: Harvard Press, 1987.

Laudon, J., and Laudon, K. Management Information Systems, Upper Saddle River, NJ: Prentice-Hall, 2005.

Lunblad, J. "A Review and Critique of Rogers' Diffusion of Innovation Theory as it Applies to Organizations," Organizational Development Journal (21), 2003, pp. 50-64.

MacIntosh, R. "BPR: Alive and Well in the Public Sector," International Journal of Operations and Production Management (23), 2003, pp. 327-344.

Mathiassen, L. "Collaborative Practice Research," Information Technology \& People (15), 2002, pp. 321-345.

McMaster, T., and Wastell, D. G. "Diffusion or Delusion? Challenging an IS Research Tradition," Information Technology \& People (18), 2005, pp. 383-404.

McMaster, T., and Wastell, D. G. "Success and Failure Revisited in the Implementation of New Technology: Some Reflections on the CAPELLA Project," in B. Fitzgerald and E. H. Wynn (eds.), Innovation for Adaptability and Competitiveness, Boston: Kluwer, 2004, pp. 313-334.

Meyer, A. D., Goes, J., and Brooks, G. R. "Organizations Reacting to Hyperturbulence," in G. Huber and W. Glick (eds.), Organizational Change and Redesign, Oxford, UK: Oxford University Press, 1995, pp. 66-111.

Mustonen-Ollila, E., and Lyytinen, K. "How Organizations Adopt Information System Process Innovations: A Longitudinal Analysis," European Journal of Information Systems (13), 2003, pp. 35-51.

Nandhakumar, J., and Avison, D. "The Fiction of Methodological Development: A Field Study of Information Systems Development," Information Technology \& People (12), 1999, pp. 176-191.

Orlikowski, W. "CASE Tools as Organizational Change: Investigating Incremental and Radical Changes in System Development," MIS Quarterly (17), 1993, pp. 309-340.

Rogers, E. M. The Diffusion of Innovations, New York: Free Press, 1995.

Seeger, M. W., Ulmer, R. R., Novak, J. M., and Sellnow, T. "Post-Crisis Discourse and Organizational Change, Failure and Renewal," Journal of Organizational Change (18), 2005, pp. 78-95.

Simon, S. J. "The Reorganization of the Information Systems of the US Naval Construction Forces: An Action Research Project," European Journal of Information Systems (9), 2000, pp. 148-162.

Slatcher, A. "Redeveloping SPRING," Internal Report, Salford City Council, 2002.

Sullivan, H., and Skelcher, C. Working Across Boundaries: Collaboration in the Public Services, Basingstoke, UK: Palgrave Macmillan, 2002.

Templeton, G. F., and Byrd, T. A. "Determinants of the Relative Advantage of a Structured SDM during the Adoption Stage of Implementation," Information Technology and Management (4), 2003, pp. 409-428.

Van der Ven, A. H. "Managing the Process of Organizational Innovation," in G. Huber and W. Glick (eds.), Organizational Change and Redesign, Oxford, UK: Oxford University Press, 1995, pp. 269-294.

Wastell, D. G. "The Fetish of Technique: Methodology as a Social Defense," Information Systems Journal (6), 1996, pp. 25-40.

Wastel1, D. G. "Information Systems and Evidence-Based Policy in Multi-Agency Networks: The Micro-Political Contingencies of Situated Innovation," Journal of Strategic Information Systems (15), 2006 (in press).

Wastel1, D. G. "Learning Dysfunctions in Information Systems Development: Overcoming the Social Defenses with Transitional Objects," MIS Quarterly (23), 1999, pp. 581-600. 
Wastell, D. G., and White, P. "Using Process Technology to Support Cooperative Work: Prospects and Design Issues," in D. Diaper and C. Sanger (eds), CSCW in Practice, Berlin: Springer-Verlag, 1993, pp. 105-126.

Wastell, D. G., White, P., and Kawalek, P. "A Methodology for Business Process Redesign: Experiences and Issues," Journal of Strategic Information Systems (3:1), 1994, pp. 23-40.

Weick, K. E. "Oganizational Redesign as Improvisation," in G. Huber and W. Glick, Organizational Change and Redesign, New York: Oford University Press, 1995, pp. 346-379..

Williams, C., and Willetts, M. "CAPELLA: CASE Tools for Process Enhancement in Local Authorities," Final Report to the European Systems and Software Initiative (ESSI), Project Number 23832, 1999.

\section{About the Authors}

David Wastell is Professor of Information Systems at Nottingham University Business School. His current research interests are in public sector reform, design and innovation, strategic alignment, and the cognitive ergonomics of complex systems. He has published widely in Information Systems, human factors, and health informatics, after an early research career in cognitive and clinical neurophysiology. He recently served on the board of European Journal of Information Systems and is currently a member of Information and Management's editorial team. David has co-organized two previous IFIP conferences (WG8.6 and WG8.2) and is program cochair for the upcoming 2007 meeting of IFIP WG8.6. He has extensive consultancy experience, especially in the public sector. He can be reached by e-mail at dave wastell@ hotmail.com.

Tom McMaster is a lecturer and researcher in the Informatics Research Centre at the University of Salford, one of the UK's leading information systems research institutes. With a variety of research interests (including technology transfer), Tom is a founding member of IFIP WG8.6, and a member of IFIP WG8.2, the UK Association for Information Systems (UKAIS), and the IRIS Association (Information Systems Research in Scandinavia). He co-organized the WG8.6 Ambleside conference in 1997, and is program cochair for the forthcoming WG8.6 conference in the UK in 2007. In 1993 Tom represented the UK at the International Conference on Inforamtion Systems' Doctoral Consortium held in Orlando, and has presented his work widely in Scandinavia, the United States, Canada, Mexico, Australia, and elsewhere. He currently serves on the editorial boards of Information Technology \& People and Journal of Information Systems Education. Tom can be reached by e-mail at T.McMaster@salford.ac.uk.

Peter Kawalek is a reader in Information Systems at Manchester Business School. He has published two books and numerous papers. Peter has considerable experience in the public sector, working with a number of cities and local councils, as well as the National Health Service and other agencies. He is a board member of the Tacit Knowledge project run by the Office of the Deputy Prime Minister in the UK. He teaches on the MBA and MSc programs in Manchester, as well as the all-Ireland MSc in Public Sector Innovation run jointly by Letterkenny Institute of Technology and the University of Ulster. Peter's extensive private sector experience includes BT, Chubb Insurance, Fujitsu, Hoverspeed, and Great North Eastern Railway.

\section{Appendix: SPRINT Headlines}

SPRINT attempts to bring together elements of good practice, from the authors' previous experience and the research literature, within a single framework. Key precepts are shown below. There are three main phases, each defined in terms of a set of aims and tasks. Phase 1 is 
essentially one of analysis, aimed at fully understanding the business context by considering all relevant perspectives, and analyzing the effectiveness of current processes. The emphasis on context is crucial, forcing the SPRINT team to "zoom out" from the original remit, which may focus too narrowly on a particular process. Two tasks are key: building formal process models using role activity diagraming, and critical goal analysis. All strands of enquiry are focused on two pivotal questions: what are the relevant business goals and how well are they supported? The aim of phase two is to devise a set of re-engineering proposals, based on a panoramic "business vision," which guides subsequent design work in which innovative reengineering opportunities are sought. The third phase of SPRINT is concerned with implementation, through training, detailed process design and development of any new IT.

SPRINT recommends two levels of governance: a steering group and the BPR team. Senior management commitment is critical, and the former should therefore include representation at director level or similar. The BPR team should comprise a senior user as project manager, together with BPR consultants, other experts, and representative end-users.

\begin{tabular}{|l|l|}
\hline \multicolumn{1}{|c|}{ SPRINT Precepts } & \multicolumn{1}{|c|}{ Comments, Rationale } \\
\hline Breadth of vision & $\begin{array}{l}\text { The methodology seeks to identify the full range of stakeholders in } \\
\text { a BPR project. SPRINT has been influenced by other methodo- } \\
\text { logies, most notably Multiview (Avison et al. 1998) which } \\
\text { acknowledge the complexity of organizational contexts and the } \\
\text { presence of multiple perspectives. }\end{array}$ \\
\hline $\begin{array}{l}\text { Depth of } \\
\text { understanding }\end{array}$ & $\begin{array}{l}\text { The development of a detailed understanding of processes through } \\
\text { rigorous empirical study (including ethnography) is vital. } \\
\text { Accounts of work given away from the scene embodied in manuals } \\
\text { typically afford idealized representations, problematically related } \\
\text { to actual practice (Wastell and White 1993). }\end{array}$ \\
\hline Radicalism & $\begin{array}{l}\text { SPRINT fully embraces Hammer's (1990) injunction to exploit the } \\
\text { potential of IT to enable radical innovation. Although radical in } \\
\text { vision, SPRINT is incremental in implementation, recognizing the } \\
\text { inherent conservatism and collegiality of public sector organi- } \\
\text { zations. }\end{array}$ \\
\hline Rigorous Assessment & $\begin{array}{l}\text { Evaluation is important to assess benefits and facilitate organi- } \\
\text { zational learning. It should follow the principles of theory-based } \\
\text { evaluation (Sullivan and Skelcher, 2002), involving the collection } \\
\text { ph quantitative and qualitative data, complemented by appropriate } \\
\text { contextual detail, to build a causal narrative. }\end{array}$ \\
\hline Flexibility & $\begin{array}{l}\text { To avoid ritualistic behavior, SPRINT is neither detailed nor } \\
\text { prescriptive; it is best described as a tool-kit providing a semi- } \\
\text { structured learning environment, or "transitional space" (Wastell } \\
\text { 1999). Case studies are provided rather than detailed step-by-step } \\
\text { prescriptions. Users are strongly encouraged to adapt the frame- } \\
\text { work, including the addition of new tools. }\end{array}$ \\
$\begin{array}{l}\text { Despite the opprobrious reputation since acquired, socio-technical } \\
\text { thinking informed early BPR approaches (e.g., Davenport, 1990). } \\
\text { SPRINT embodies this same human-centered outlook, emphasizing } \\
\text { the non-Tayloristic use of technology to empower and augment the } \\
\text { role of humans, not to automate and replace them. }\end{array}$ \\
\hline and
\end{tabular}

